\title{
Identification of Drought and Performance Evaluation of MODIS and TRMM through Remote Sensing: A Case Study in North and West Africa during 2002-2018
}

\author{
Malak Henchiri 1,2,3, Qi Liu 2, Bouajila Essifi ${ }^{4}$, Shahzad Ali ${ }^{2}$, Wilson Kalisa 1,2, Sha Zhang, ${ }^{2}$, Yun \\ Bai ${ }^{2}$, Jiahua Zhang,** \\ 1 School of Automation, Qingdao University, Qingdao 266071, China; malakhenchirii@gmail.com \\ 2 Remote Sensing Information and digital Earth Center, School of Computer Science and Technology, \\ Qingdao University, Qingdao 266071, China; sealiuqi@163.com ; shahzadali320@aup.edu.pk ; \\ wilsonkalisa03@yahoo.com ; zhangsha@qdu.edu.cn; baiyun@qdu.edu.cn \\ ${ }^{3}$ Key Laboratory of Digital Earth Science, Institute of Remote Sensing and Digital Earth, Aerospace \\ Information Research Institute, Chinese Academy of Sciences, 100094 Beijing, China; zhangjh@radi.ac.cn \\ ${ }^{4}$ Institut des Regions Arides (IRA), 4119 Medenine, Tunisia; essifib@gmail.com \\ * Correspondence: zhangjh@radi.ac.cn; Tel.: +86-1368-357-6879 (J.Z.)
}

\begin{abstract}
North and West Africa are the most vulnerable regions to drought, due to the high variation in monthly precipitation. An accurate and efficient monitoring of drought is essential. In this study, we use TRMM data with remote sensing tools for effective monitoring of drought. The Drought Severity Index (DSI), Temperature Vegetation Drought Index (TVDI), Normalized Difference Vegetation Index (NDVI), and Normalized Vegetation Supply Water Index (NVSWI) are more useful for monitoring the drought over North and West Africa. To classify the areas affected by drought, we used the TRMM spatial maps to verify the TVDI, DSI and NVSWI indexes derived from MODIS. The DSI, TVDI, NVSWI and Monthly Precipitation Anomaly (NPA) indexes with the employ of MODIS-derived ET/PET and NDVI were chosen for monitoring the drought in the study area. The seasonal spatial correlation between the DSI, NPA, NVWSI, NDVI, TVDI and TCI indicates that NVSWI, NDVI and DSI present an excellent monitor of drought indexes. The change trend of drought from 2002 to 2018 was also characterized. The frequency of drought showed a decrease during this period.
\end{abstract}

Keywords: North and West Africa; Drought; DSI; TVDI; NVSWI; Spatial Correlation; Change Trend of Drought.

\section{Introduction}

Drought is one of the most disruptive natural hazards, which is caused by water deficits and has far-reaching impacts on agriculture, society, ecosystems and economy $[1,2]$. These impacts may be direct (i.e., reduced crop yield or water use restrictions) or indirect (i.e., increased food costs due to reduced crop yield) [3,4]. A number of studies have shown that drought episodes have been recurring for several years in Africa [5-13]. And these studies show that drought can last for several years in a row, it is a permanent phenomenon in Africa, which frequently appears at an unpredictable frequency. People in Africa have integrated drought into their crops and farming systems $[14,15]$. Climatologically, the origin of rainfall in Africa is attributable to the advection of moist air (essentially evaporation of water from the Indian and Atlantic Oceans) and that their variation depends on anomalies of the general circulation of the atmosphere, may be reinforced by the increase in albedo due to the degradation of vegetation in Africa [5]. Naumann et al. [11] have 
mentioned that during 2010-2011 period, drought in Africa affected more than 12 million people and resulted in massive migration, extreme hunger and the mortality of more than 260.000 people. The detection of drought severity needs constant monitoring of drought in order to better mitigate its possible negative effects on the environment. Many studies have used climatic drought indexes from station-based meteorological data sets or Remote Sensing (RS) based drought indexes [16-18]. An accurate and timely monitoring of drought is required for detecting the global change on drought [19].

Satellite remote sensing has a particularly effective for drought monitoring [20]. Generally, Normalized Difference Vegetation Index (NDVI) is used to monitor the drought and vegetation, and to evaluate the crop yield loss [21]. Although, the drought event does not depend only with the variation of green vegetation; sometimes there is a gap between vegetation indexes and the actual frequency of drought. Sandholt et al. [22] developed TVDI (Temperature Vegetation Drought Index) calculated using NDVI and Land Surface Temperature (LST) data to analyses the spatial pattern and temporal evolution of TVDI from 1990 covering part of the Ferlo region of northern, semiarid Senegal in West Africa, and Dhorde and Patel [23] have used the TVDI to investigate spatial trends in terminal drought over western India comprising the states of Rajasthan and Gujarat which are characterized by semi-arid to arid climate. The Vegetation Supply Water Index (VSWI) from the division of NDVI and LST was used to ascertain surface soil moisture availability and fractional vegetation cover [24]. This standardized VSWI can indicate current soil conditions compared to other recorded periods, i.e. the severity of drought on an absolute scale. For example, the NVSWI of Abbas et al. [25] (Eq. (11)) describes relative drought conditions between the years, with an NVSWI of zero indicating the most severe drought during the study period and an NVSWI of 1 indicating the wettest conditions. These indexes are typically used to monitor drought in past years [20]. However, TVDI is exactly present the state of drought because it relies on statistical analysis [22]. Researchers have highlighted the thermal stress on the soil surface, which has resulted in an LST-based Temperature Condition Index (TCI) [22]. Also, some studies discovered that the association of temperature with vegetation was an important indicator for drought monitoring.

Recently, some indexes such us DSI, NVSWI and TVDI are related to the correlation between ET/PET and NDVI. Remote sensing data is the best tools to monitor the drought over a large scale area [26]. The Tropical Rainfall Measuring Mission (TRMM) is a joint mission between NASA and the Japan Aerospace Exploration (JAXA) Agency to study rainfall for weather and climate research, and Chen et al. [19] have used TRMM coupled with soil moisture data to monitor the temporal and spatial change of drought from the winter of 2010 to the spring of 2011.

The DSI index for evapotranspiration (ET), potential evapotranspiration (PET) and NDVI was developed by $\mathrm{Mu}$ et al. [27]. Xu et al. [28] mentioned that the MODIS-based ET product performs extremely well in numerous studies and it presents a significant sign to monitor the drought over a large area. The NDVI index has the potential to link the vegetation response to the climate change [29]. The NDVI data with ET data were jointly incorporated to define the DSI. In addition, drought has a high interaction with temperature, ET, and rainfall. For example, a drought index can be proper for one region and not suitable for other regions, which require verification study in different geographical regions. There are many studies to rank the durability and fragility of these drought indexes [27].

In recent years, the North and West Africa regions are particularly threatened by drought and significantly affected by the climate change [5]. Waha et al. [30] demonstrated that the drought disaster can have a significant impact on the global environment and local agriculture. If the drought persists and the resource exploitation patterns did not change, the impacts of drought will increase in the next few years [31]. However, Dianmin et al. [18] studied the drought conditions and the capability of drought indexes vary substantially in many regions. For all these raisons, it's important to evaluate the performance of some drought index for accurately monitoring the drought events over North and West Africa.

In current study, the main objectives were: 1) to evaluate the performance of the seasonal TRMM satellite rainfall data with the seasonal DSI, TVDI and NVSWI indexes derived from MODIS 
to monitor the drought events over North and West Africa. 2) To identify which drought index was good indicators for drought monitoring in North and West Africa. 3) To explore the temporal-spatial patterns and the change trend of drought over North and West Africa during the period 2002-2018.

\section{Materials and Methods}

\subsection{Study area}

This study was applied over North and West of Africa; it lies between latitudes $4^{\circ}$ and $38^{\circ} \mathrm{N}$, and longitudes $18^{\circ} \mathrm{W}$ and $40^{\circ} \mathrm{E}$. The study area is surrounded by the Mediterranean Sea in the North, the Red Sea in the East, the Central and East Africa in the Southeast and the Atlantic Ocean in the West and Southwest (Figure 1).

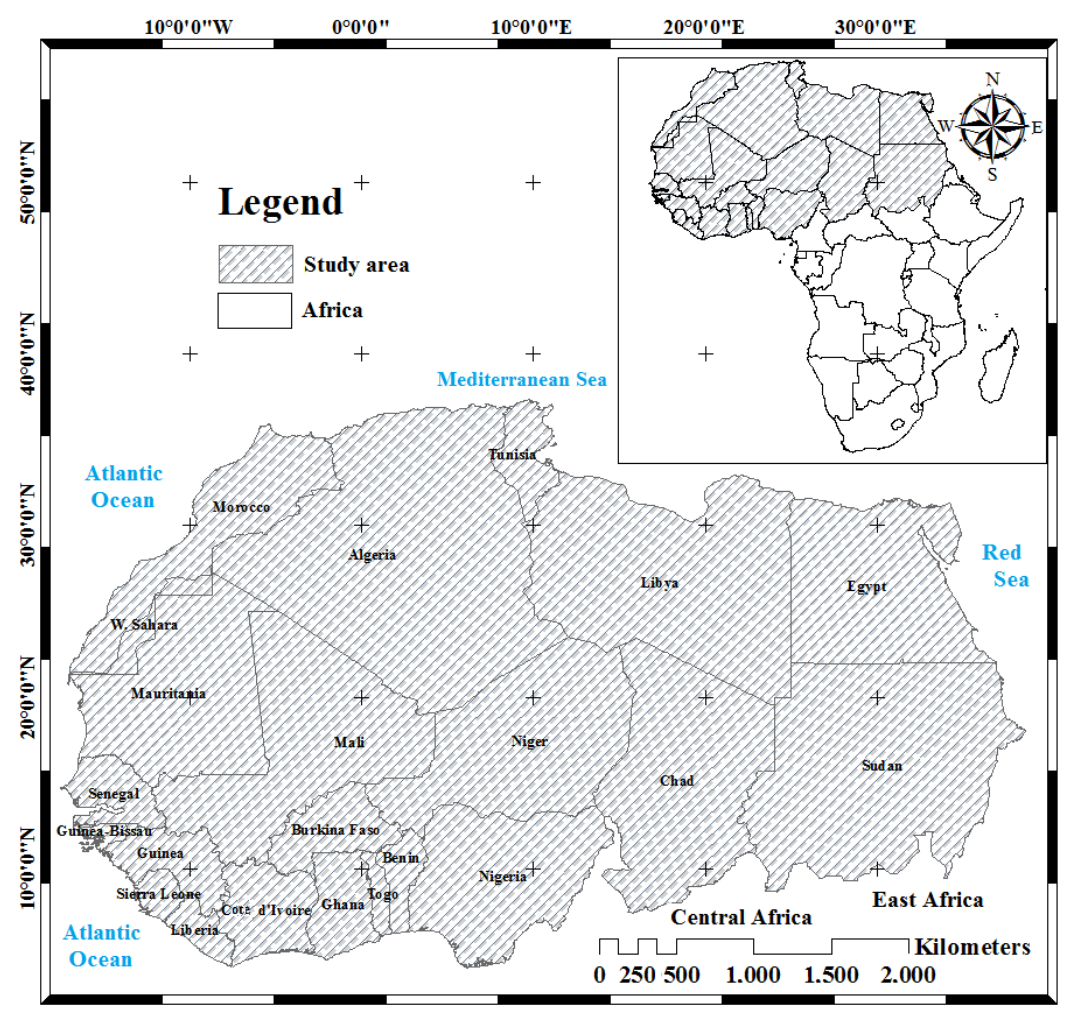

Figure 1. Study area

Figure 2 clearly presents the land cover in North and West Africa. The distribution of the land cover ranges from Mediterranean to tropical, the central zone is desert or arid, while, its southern regions include both savannas plains. Between the two, there are combinations dominated by vegetation types [32]. 


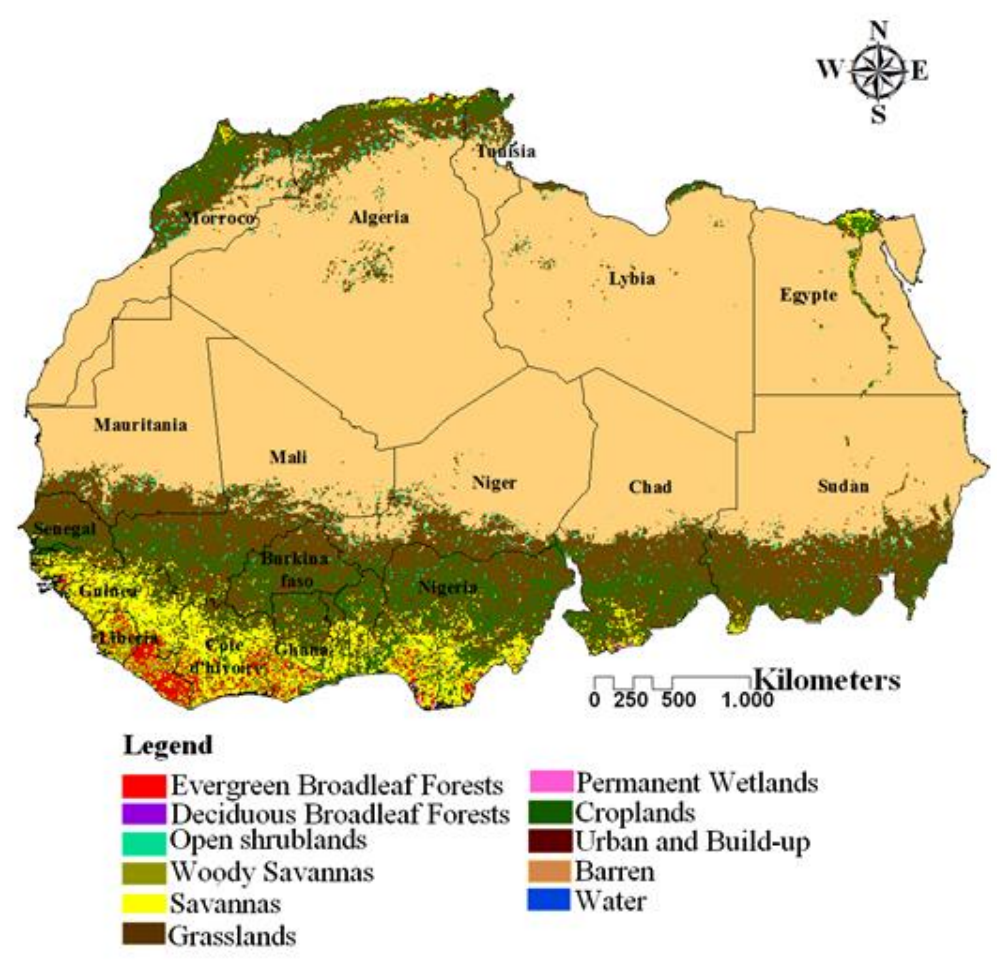

Figure 2. Land cover map in North and West Africa

\subsection{Data and Pre-Processing}

In this study, the primary data sets used consist of three MODIS products, namely NDVI, LST and ET/PET and one TRMM product 3B43. The NDVI and the LST data were used to develop the NVSWI [33]. In this study, the monthly MODIS NDVI standard product (MOD13A1, $1 \mathrm{~km} \mathrm{spatial}$ resolution) during 2002-2018 was downloaded from the National Aeronautics and Space Administration (NASA) https://ladsweb.modaps.eosdis.nasa.gov. These NDVI time series data were cleaned and smoothed using a median filtration for suppressing disturbances. The MODIS LST products data have been validated and are considered ready to use in scientific analysis [34]. In this work, the LST dataset from the Terra MODIS 8-day LST composite during 2002 to 2018 with $1 \mathrm{~km}$ spatial resolution (MOD11A2, collection v005) was used. The 8-day product is based on an average of "two to eight days" LST estimated with clear-sky conditions [35]. The rainfall product 3B43 of the TRMM dataset was used, it covers the latitude band extends from $50^{\circ}$ South to $50^{\circ}$ North with $0.25^{\circ} \times$ $0.25^{\circ}$ spatial resolution, and is given as monthly precipitation rate $(\mathrm{mm} / \mathrm{h})$. The TRMM dataset from 2002 to 2018 were obtained from NASA and Information Services Center (DISC) (http://mirador.gsfc.nasa.gov/). In this study, the TRMM data were resampled to $1 \mathrm{~km}$ spatial resolution and used to calculate the index NPA [36]. The ET and PET provided in MOD16A2 Version 6 at 8-day composite dataset produced at $500 \mathrm{~m}$ spatial resolution during 2002-2018 were used. They were obtained from the NASA's Earth Observing System Data and Information System (EOSDIS) (http://reverb.echo.nasa.gov/). To match the NDVI composite temporal resolution, we composited consecutive 8-day ET and ETP images to monthly images. Then, resampled to $1 \mathrm{~km}$ spatial resolution. These two data were used to derive the DSI monthly values.

\subsection{Drought severity index (DSI)}

The calculation of DSI index based on the idea of using a continuous remotely sensed data available from polar orbiting satellites to improve our drought monitoring capabilities detailed by Mu et al. [27]. For this purpose, monthly MODIS NDVI product (MOD13A1) and MODIS ET/PET (MOD16A2) at $1 \mathrm{~km}$ spatial resolution was used to derive DSI monthly values. The ratio (ET/PET) could be used as an indicator for wetness or dryness in a region. It was calculated as: 


$$
\text { Ratio }=\frac{\mathrm{ET}}{\mathrm{PET}}
$$

The temporal $(\overline{\text { Ratio }})$ and standard deviation ( $\sigma$ Ratio $)$ of ratio were calculated during 2002-2018.

$$
\mathrm{Z}_{\text {Ratio }}=\frac{\text { Ratio- } \overline{\text { Ratio }}}{\sigma_{\text {Ratio }}}
$$

Similarly, NDVI values at each grid cell were normalized by $(\overline{\mathrm{NDVI}})$ and standard deviation (бNDVI) to get ZNDVI:

$$
\mathrm{Z}_{\mathrm{NDVI}}=\frac{\mathrm{NDVI}-\overline{\mathrm{NDVI}}}{\sigma_{\mathrm{NDVI}}}
$$

The summation of both $Z_{\text {Ratio }}$ and ZNDVI values was carried out to get value:

$$
\mathrm{Z}=\mathrm{Z}_{\text {Ratio }}+\mathrm{Z}_{\mathrm{NDVI}}
$$

The normalized value that is called DSI was finally calculated as:

$$
\mathrm{DSI}=\frac{\mathrm{Z}-\overline{\mathrm{Z}}}{\sigma_{\mathrm{Z}}}
$$

It has a potential advantage over other drought indexes because it incorporated vegetation and transpiration data into its computation. The standardized nature of the DSI could classify droughts according to their severity (Table 1) provided Mu et al. [27].

Table 1. Drought categories for DSI

\begin{tabular}{rrrrrrr}
\hline & Extreme & Severe & Moderate & Slight & Normal & Wet \\
\hline DSI & $>-1.5$ & -1.5 to -1.2 & -1.2 to-0.9 & -0.9 to -0.3 & -0.3 to 0.9 & $>1$ \\
\hline
\end{tabular}

2.4. Temperature vegetation drought index (TVDI)

Following the concept of Figure 3, the isolines can be drawn in the triangle defining the LST/NDVI space [37].

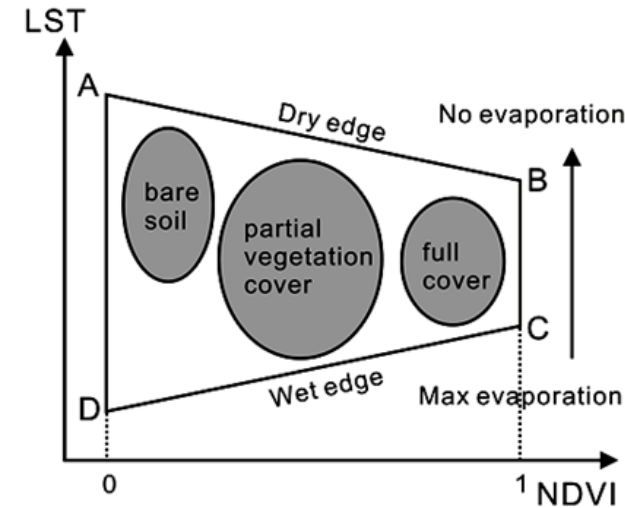

$\mathbf{a}$

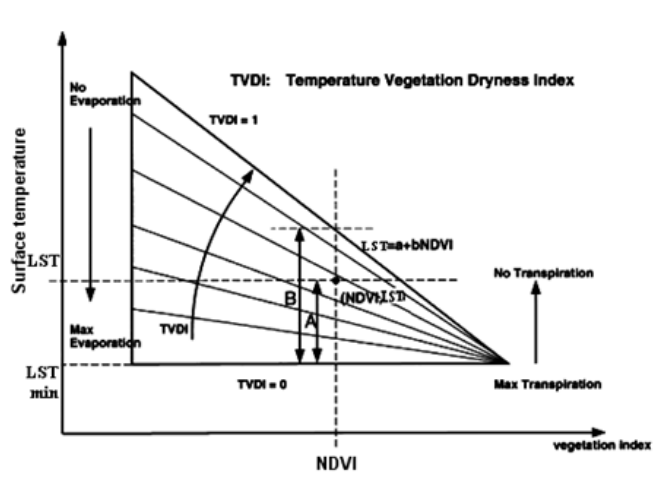

b

Figure 3. Definition of the TVDI (Sandholt et al. 2002)

During the first iteration, the information will be obtained on the soil moisture content at the surface: a dryness index (TVDI) of 1 on the "dry edge" (limited water availability) and 0 at "the wet edge" (maximum evapotranspiration and therefore unlimited access to water) can be defined:

$$
\text { TVDI }=\frac{\mathrm{LST}_{-} \mathrm{LST}_{\min }}{\mathrm{LST}_{\max }-\mathrm{LST}_{\min }}
$$

LST $_{\min }$ is the lower horizontal line of the triangle, represent the wet edge; LST $_{\max }$ is the maximum surface temperature, represent the dry edge:

$$
\begin{aligned}
& \mathrm{LST}_{\text {min }}=\mathrm{a} 1+\mathrm{b} 1 \times \mathrm{NDVI} \\
& \mathrm{LST}_{\text {max }}=\mathrm{a} 2+\mathrm{b} 2 \times \mathrm{NDVI}
\end{aligned}
$$

Where $a 1, b 1$ and $a 2, b 2$ are the coefficients of the wet edge and the dry edge equations determined by linear regression. The TVDI values were categorized into five intensity categories (Table 2) provided by Zhang et al. [38].

The TCI was determined by the following formula Kogan [39]: 


$$
\mathrm{TCI}=\frac{\mathrm{LST}_{\max }-\mathrm{LST}}{\mathrm{LST}_{\max }-\mathrm{LST}_{\min }}
$$

Where $\mathrm{LST}_{\max }$ and $\mathrm{LST}_{\min }$ are the maximum and the minimum LST values of each pixel.

Table 2. Drought categories for TVDI

\begin{tabular}{llllll}
\hline & Normal & Slight & Moderate & Severe & Excessive \\
\hline TVDI & $0-0.67$ & $0.67-0.74$ & $0.74-0.80$ & $0.80-0.86$ & $0.86-1.00$ \\
\hline
\end{tabular}

\subsection{TRMM product 3B43 rainfall}

The TRMM 3B43 monthly rainfall from 2002 to 2018 was downloaded from the NASA's Earth Observation System Data and Information System (http://reverb.echo.nasa.gov/). This product extends from $50^{\circ} \mathrm{N}$ to $50^{\circ} \mathrm{S}$ at a spatial resolution of $0.25^{\circ}$. The data were resampled to $1 \mathrm{Km}$ resolution and calculated the index NPA.

\subsection{NVSWI}

When the vegetation suffers from drought and lack of water, leaf stomata will close to maintain water in the canopy. As a result, the evapotranspiration decreases and the LST increase. Based on the assumption that, with sufficient soil water supplies, the TST observed on the vegetation will be lower due to the evapotranspiration, than that observed on bare land. The NVSWI is determined by the following formula [24]:

$$
\mathrm{VSWI}=\frac{N D V I}{L S T}
$$

Since VSWI can only represent the relative spatial location and is not comparable on the time series, the NVSWI has been advanced and calculated using the following formula [25]:

$$
\mathrm{NVSWI}=\frac{\mathrm{VSWI}-\mathrm{VSWI} \min }{\mathrm{VSWI}_{\max }-\mathrm{VSWI}_{\min }}
$$

Where VSWImin and VSWImax are minimum and maximum value of VSWI of each pixel during the period of study. The NVSWI values were categorized into five intensity categories (Table 3) provided by Abbas et al. [25].

Table 3. Drought categories for NVSWI.

\begin{tabular}{lllccc}
\hline & Severe & Moderate & Slight & Normal & Wet \\
\hline NVSWI & $<0.20$ & $0.20-0.40$ & $0.40-0.60$ & $0.60-0.80$ & $>0.80$ \\
\hline
\end{tabular}

\subsection{NPA}

The percentage of monthly Precipitation Anomaly (PA) is the precipitation deficit over the mean value for the same period. It is calculated with the following formula [40]:

$$
\mathrm{PA}=\frac{\mathrm{P}-\overline{\mathrm{P}}}{\overline{\mathrm{P}}} \times 100
$$

Where $\mathrm{P}$ represents the current precipitation, $\bar{P}$ represents the mean precipitation during the same period. The PA can be used to monitor drought by the degree of deviation from the mean precipitation. The values of the PA can be positive or negative. A percentage of monthly Precipitation Anomaly (NPA) with values from 0 to 1 could be derived using the following equation:

$$
\mathrm{NPA}=\frac{\mathrm{PA}-\mathrm{PA}_{\min }}{\mathrm{PA}_{\max }-\mathrm{PA}_{\min }}
$$

Where PAmin and PAmax are the minimum and the maximum values of the NPA.

\subsection{Drought Frequency}

The Drought frequency (Fi) presented in the following formula (using monthly NVSWI) was used to identify the most severe drought years between 2002 and 2018.

$$
\mathrm{F}_{\mathrm{i}}=\frac{\mathrm{n}_{\mathrm{i}}}{\mathrm{N}}
$$

Where ni is the series number of the month and $\mathrm{N}$ the length of the time series.

2.9. Tendency rate of drought 
To analyze whether the drought as increasing or decreasing from 2002 to 2018 in our study area, the tendency drought rate was calculated based on the monthly NVSWI data. It was calculated with the following formula:

$$
\text { Slope }=\frac{\mathrm{n} \sum_{\mathrm{i}}^{\mathrm{n}}\left(\mathrm{i} \times \mathrm{F}_{\mathrm{i}}\right)-\left(\sum_{\mathrm{i}=1}^{\mathrm{n}} \mathrm{i}\right) \times\left(\sum_{\mathrm{i}=1}^{\mathrm{n}} \mathrm{F}_{\mathrm{i}}\right)}{\mathrm{n} \sum_{\mathrm{i}=1^{\mathrm{n}}}^{\mathrm{n}} \mathrm{i}^{2}\left(\sum_{\mathrm{i}=1}^{\mathrm{n}} \mathrm{i}\right)^{2}}
$$

Where $\mathrm{i}$ is the series number of the year, $\mathrm{n}$ is the length of the time series, $\mathrm{F}$ is the frequency of droughts in the year i. If the slope is positive, it means that the frequency of droughts increases and the degree of drought worsens during the time series. While, the negative slope showed that the degree of drought increased over the time series.

\subsection{Spatial Correlation Analysis}

The seasonal time series of all the variables were used for correlation analysis $\left(\mathrm{r}_{\mathrm{x} y}\right)$. The result shows where the vegetation can respond significantly to climate variability, which is important for understanding climate change.

$$
r_{x y}=\frac{\sum_{i}\left(x_{i}-\bar{x}\right)\left(y_{i}-\bar{y}\right)}{\sqrt{\sum_{i}\left(x_{i}-\bar{x}\right)^{2} \sum_{i}\left(y_{i}-\bar{y}\right)^{2}}}
$$

Where $y$ and $x$ are the predictor (climate) and response (NDVI) variables, respectively.

\section{Results}

3.1. DSI for the characterization of drought events

The annual values of the DSI in North and West Africa during 2002-2018 were mapped separately for each year in order to classify the areas affected by drought (Figure 4). The average seasonal DSI maps were made over the entire study period; however, to classify these years of severe drought such as 2002, 2009, 2010 and 2016, seasonal data are presented (Figure 5). It has been studied that, for the short-term dry period, the seasonal differences in DSI values are very important.
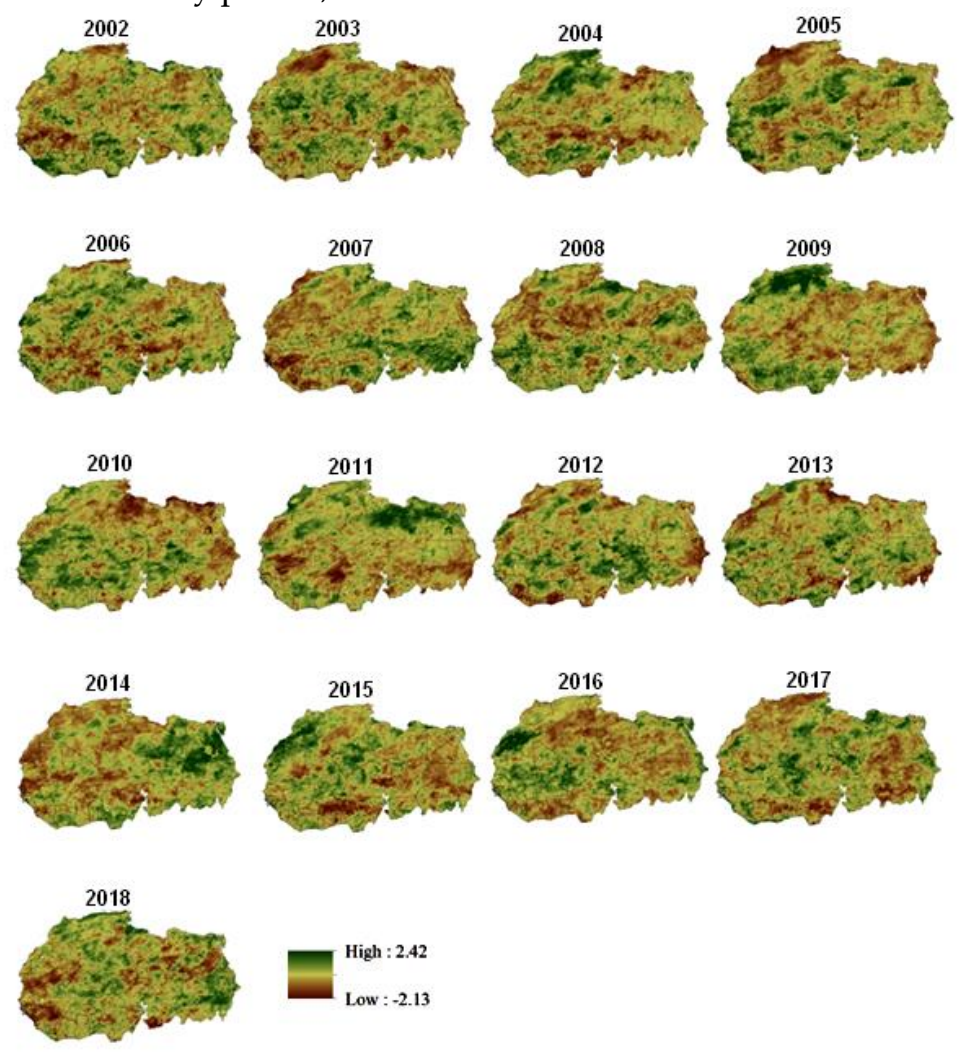

Figure 4. Annual drought severity index (DSI) anomaly values over North and West Africa for the period of 2002 to 2018. 
On a regional scale, the drought-based DSI maps are easy to understand in terms of drought severity due to identify the values calculated. The DSI values equal to or greater than 1.5 are considered as severe wet situation and values of -1.5 or below are considered severe drought conditions [27].

The development of severe dry and wet situations could be a study of DSI distribution values. The spatial maps indicate that the severe drought is developing in winter season of 2010 (DJF) in West Africa; but in North Africa, the severe drought occurred in 2016 during the summer season (JJA), which explains the impact of normal monsoon rainfall in West Africa during the Summer [31]. This provided sufficient rainfall for vegetation growth in West Africa region. As a result, in the summer season water shortages are only visible in northern Africa. The drought during the spring season (MAM) covers most of the agricultural areas of West Africa. Against in the northern regions of the study area was the growing season during this period. The northern regions were again under the effect of dry circumstances during autumn season (SON). The DSI of negative anomaly is associated with drought and the positive values are related to witness while, the legend indicates the respective years. The spatial distribution of DSI has identified areas affected by extreme drought during 2002, 2009, 2010 and 2016. The maps indicated that, among all these years, the dry conditions of 2010 were the worst, which revealed the value of the low anomaly DSI (-2.10) in our study area.

\subsection{TVDI, NVSWI, and NPA for the characterization of drought}

In order to select the most appropriate drought indexes in the study area, the performances of three frequently used indexes were evaluated, such as TVDI, NVSWI and NPA. In order to specifically describe the degree of drought, two indexes such as TVDI and NVSWI were classified into five levels: wetness drought, normal condition, slight drought, moderate drought, and extreme drought. In addition, the seasonal averages of TVDI, NVSWI, and NPA with four years of extreme drought (2002, 2009, 2010 and 2016) were sequentially selected to test the monitoring capability of drought indexes.

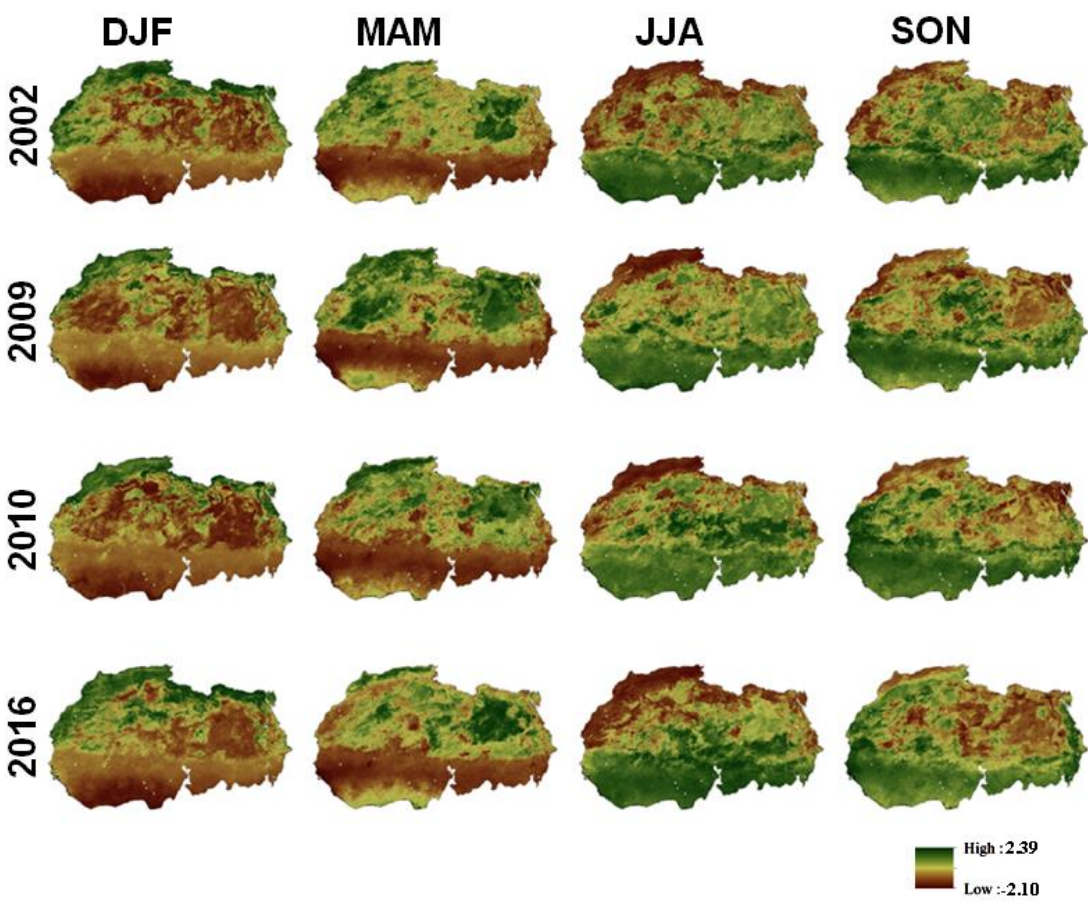

Figure 5. Seasonal average DSI distribution for the historic drought event, DJF: Dec-Feb, MAM: Mar-May, JJA: Jun-Aug and SON: Sep-Nov, over North and West Africa during 2002, 2009, 2010, 
The spatial distribution patterns of various drought indices in North and West Africa are illustrated in Figures. 6, 7 and 8. The correlation analysis between the drought indexes justified the advantage of using the NVSWI index. In addition, the NPA index was used in the previous studies to determine the performance of the drought index [41,42].

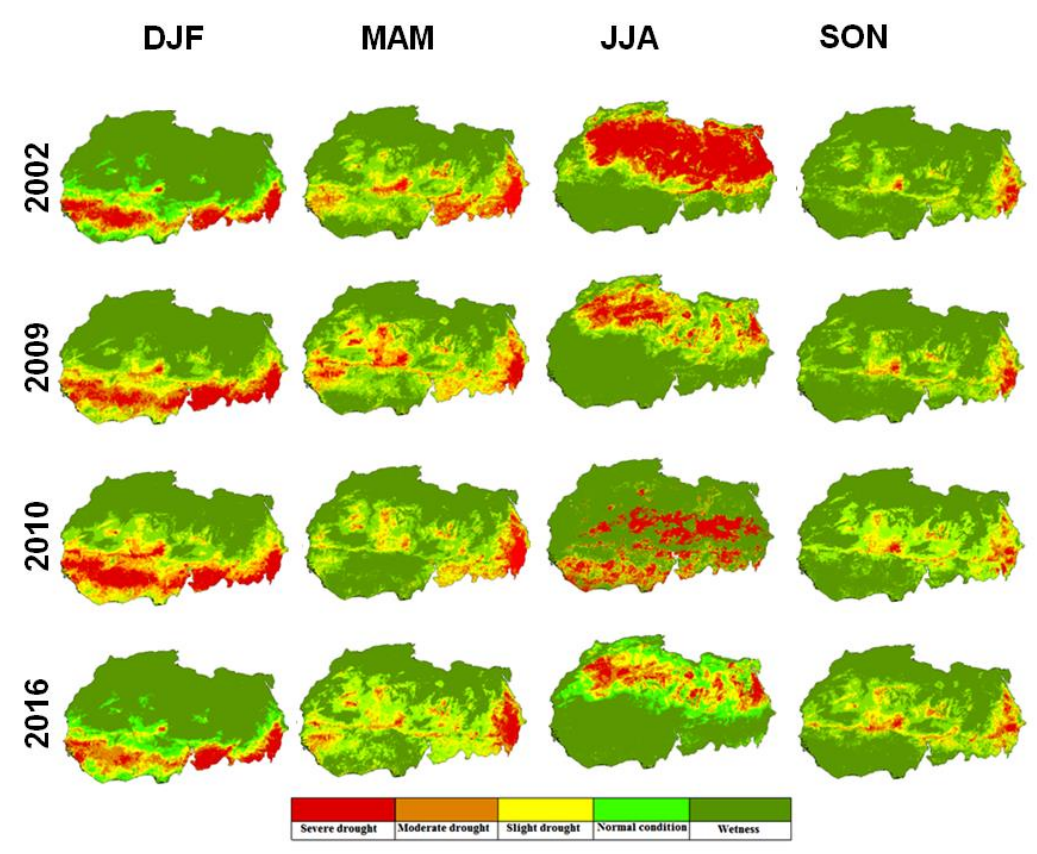

Figure 6. Spatial pattern of seasonal average TVDI values, DJF: Dec-Feb, MAM: Mar-May, JJA:

Jun-Aug and SON: Sep-Nov, over North and West Africa during 2002, 2009, 2010, and 2016.

The validity of the TRMM has also been determined by several existing studies in other regions [43]. During various growing seasons, the analysis of the spatial distribution of three different indexes varies significantly. The regions of northern Africa and their environs were recognized by TVDI and NVSWI as a wet region during the winter season (DJF), for the regions of West Africa, they show a higher drought rates during this season. Against, during the summer season (JJA) the severe drought is observed in all regions of northern Africa and in the great Sahara of Africa, and for the West Africa regions is presented by a growth of vegetation, this may be due to the high vegetation cover due to the high NDVI value and the monsoon rainfall. The NVSWI index showed that the drought is very severe during 2016 in spring season (MAM) and covers a large area throughout the study area. The NPA indicated the opposite, which could be a result of high LST and low rainfall for NPA. The distribution patterns of NPA were inconsistent due to the irregular distribution of precipitation (Fig. 8). As a result, the distribution of TVDI and NVSWI (Figures 6 and 7) performed better out of the three drought indexes. The distribution maps of TVDI and NVSWI indicated that over the study area, the more dry condition settled during the winter and the summer seasons. The monsoon rains started during the Summer (JJA) season, which provided sufficient soil water for the growth of plants in West Africa and water shortage was only observable in North Africa. On the contrary, during the winter season (DJF), the growth of vegetation is present in North Africa and drought is occurring in West Africa. To measure drought over the study area, the NVSWI index is recognized as the most satisfactory index among the three indexes examined. Many previous studies have also monitored the drought using the NVSWI index $[25,44]$. The NVSWI index was normally based on VSWI, which has a more satisfactory index for monitoring drought over large areas [25]. In addition, NPA drought monitors only monitor rainfall; this could have very small variations in some months with low rainfall in the study area, and NPA cannot monitor the degree of drought $[40,45]$. 


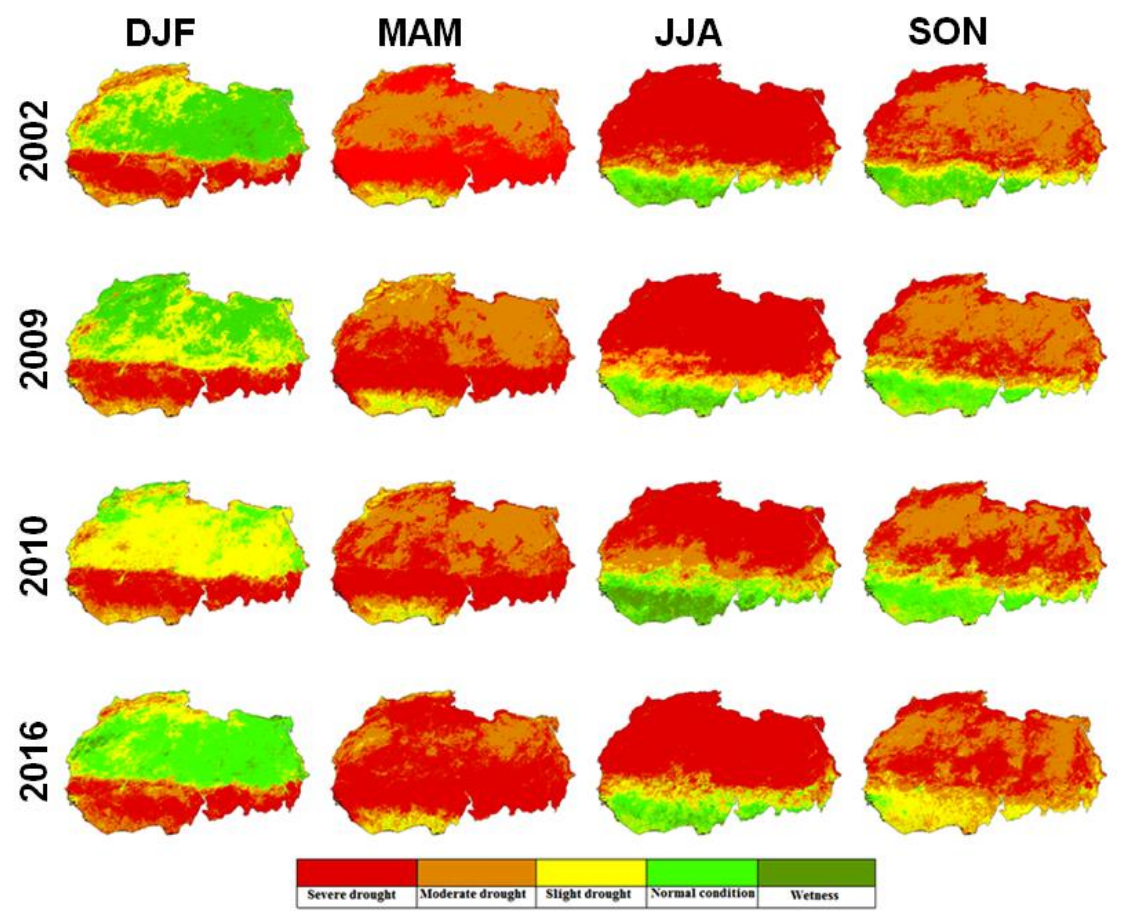

Figure 7. Spatial distribution of seasonal average NVSWI values, DJF: Dec-Feb, MAM: Mar-May, JJA: Jun-Aug and SON: Sep-Nov, over North and West Africa during 2002, 2009, 2010, and 2016.
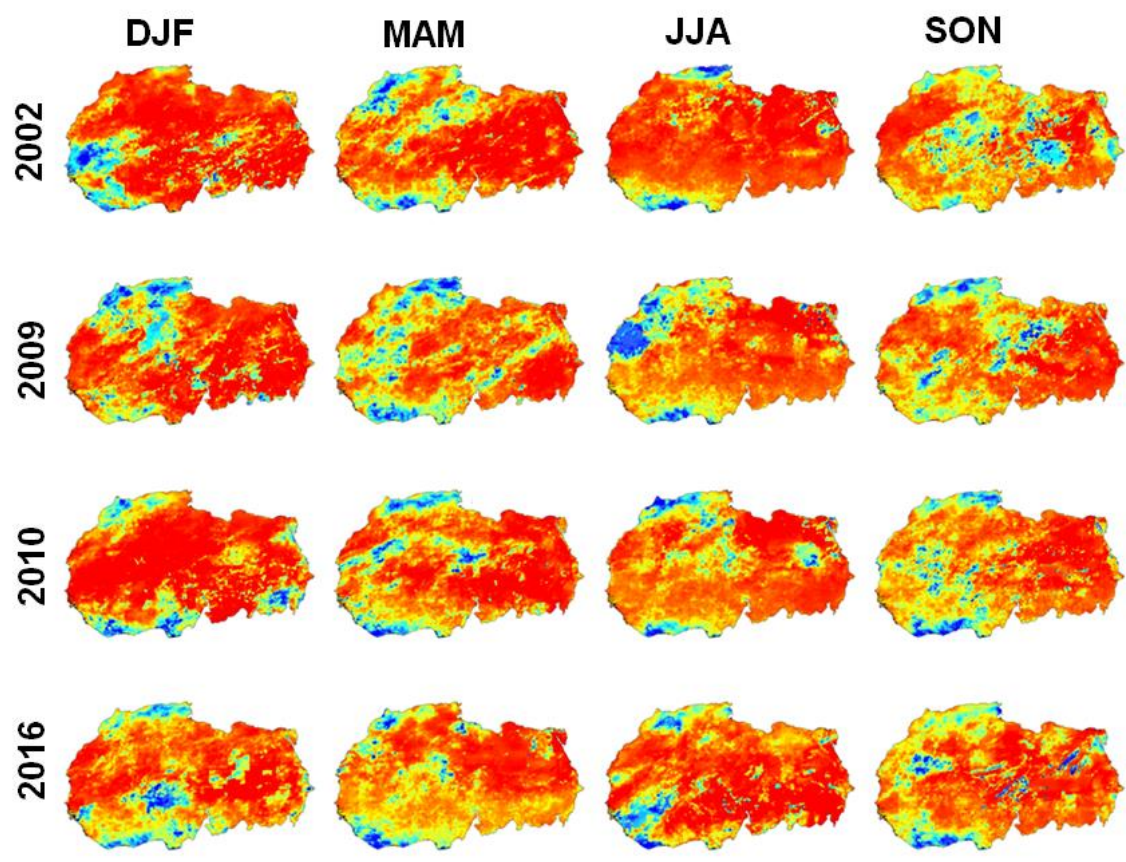

High : 1
Low : 0

Figure 8. Spatial distribution of seasonal average NPA values, DJF: Dec-Feb, MAM: Mar-May, JJA: Jun-Aug and SON: Sep-Nov, over North and West Africa during 2002, 2009, 2010, and 2016.

3.3. NDVI for the characterization of drought 
In this study, to analyze the seasonal mean NDVI value, we used the MODIS monthly NDVI product. The value of NDVI closed to zero indicates that the climate is related to drying with low vegetation cover (Figure 9). To classify the arid regions of North and West Africa, the average seasonal NDVI was assessed and recognized. The NDVI seasonal average maps for the years 2002, 2009, 2010 and 2016 are shown for the general dynamics of vegetation (Figure 9). The vegetation cannot grow very well in a large part of the study area, especially in the Sahara part of Africa, which expected less rainfall and was under water deficit conditions. The seasonal NDVI maps in North and West Africa regions were established throughout the study period to show areas severely affected by drought. Wang et al. [46] confirmed that the value of NDVI depends on climatic characteristics, such as, rainfall and LST that could be used to monitor climatic drought. The maps of the distribution patterns of NDVI have confirmed that, the dry conditions have shown in North Africa during the summer season (JJA) and in West Africa during the winter season (DJF) due to the summer monsoon rains (JJA) which provide sufficient water for the growth of vegetation in this region. The value of NDVI in North Africa is higher during the winter season (DJF) and from spring to summer, the values of NDVI tend to decrease, while, in West Africa it is higher during the summer season (DJF) and from autumn to spring, the NDVI values show a declining trend.

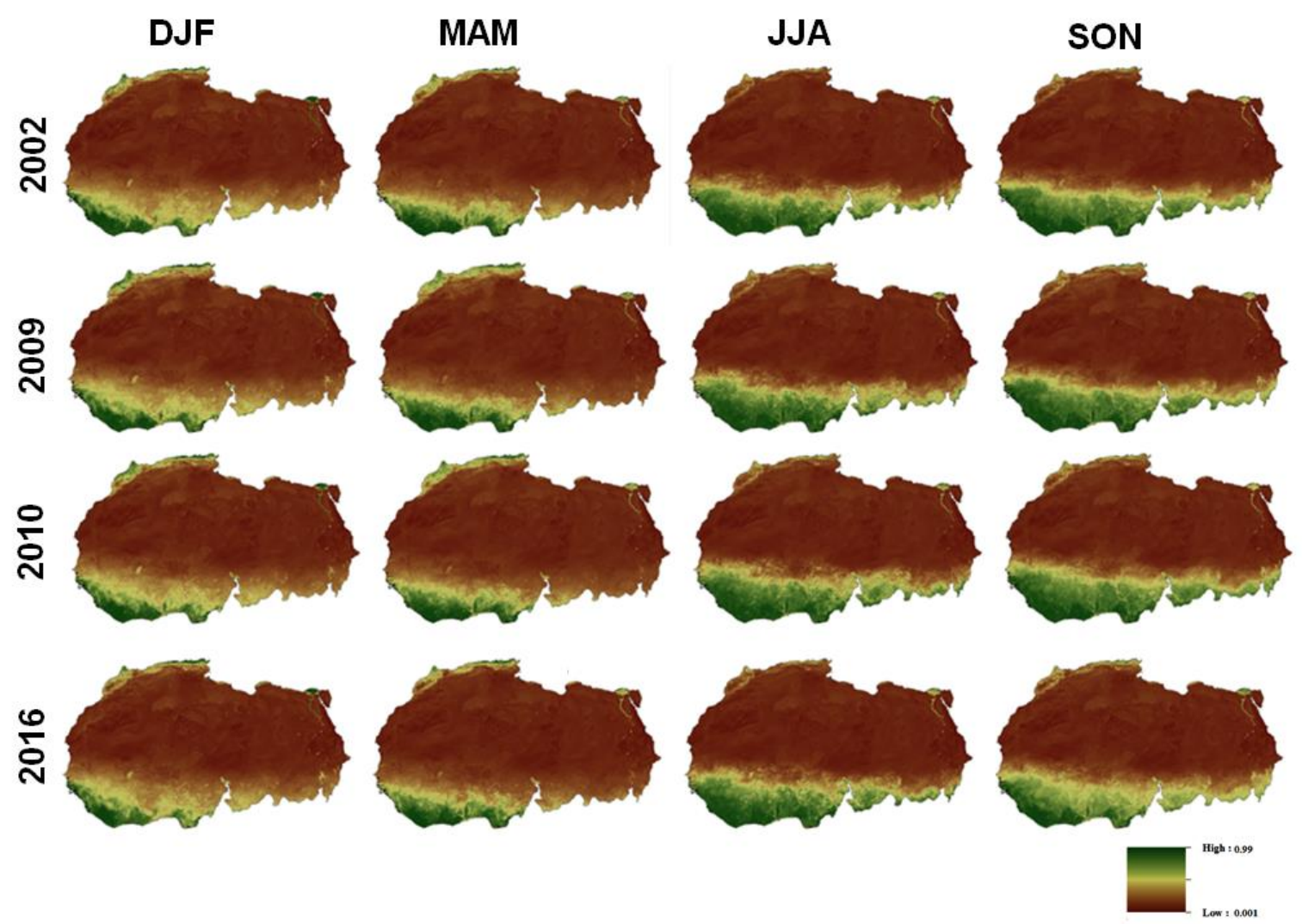

Figure 9. Spatial distribution of seasonal average NDVI values, DJF: Dec-Feb, MAM: Mar-May, JJA:

Jun-Aug and SON: Sep-Nov, over North and West Africa during (2002-2009-2010-2016).

3.4. Drought change trend in North and West Africa during 2002-2018

In order to characterize the change trend of drought from 2002 to 2018, the frequency of droughts, including severe droughts, moderate droughts and slight drought, were calculated based on the monthly NVSWI data from 2002 to 2018. Then, the drought rate of each year and the trend of drought between 2002 and 2018 were calculated. Figure 10 shows the frequency of drought from 2002 to 2018 in the study area, which validates our choice for the more severe drought years (2002, 2009, 2010 and 2016). The highest frequency of drought was observed in 2010 (86.59\%), the lowest frequency of drought was observed in 2014 (74.86\%) which could be due to the maximum amount of rainfall. The slope of the fitting line is negative, with a value of -0.069 , indicating that the frequency of droughts has decreased from 2002 to 2018. Figure 11 shows the distribution of the drought slope 
in North and West Africa. The degree of drought has decreased in the study area over the last 17 years. The drought affected the central part of the study area "the big Sahara" during all this period. For the North and the West part of Africa the more severe drought years was 2002, 2009, 2010 and 2019.

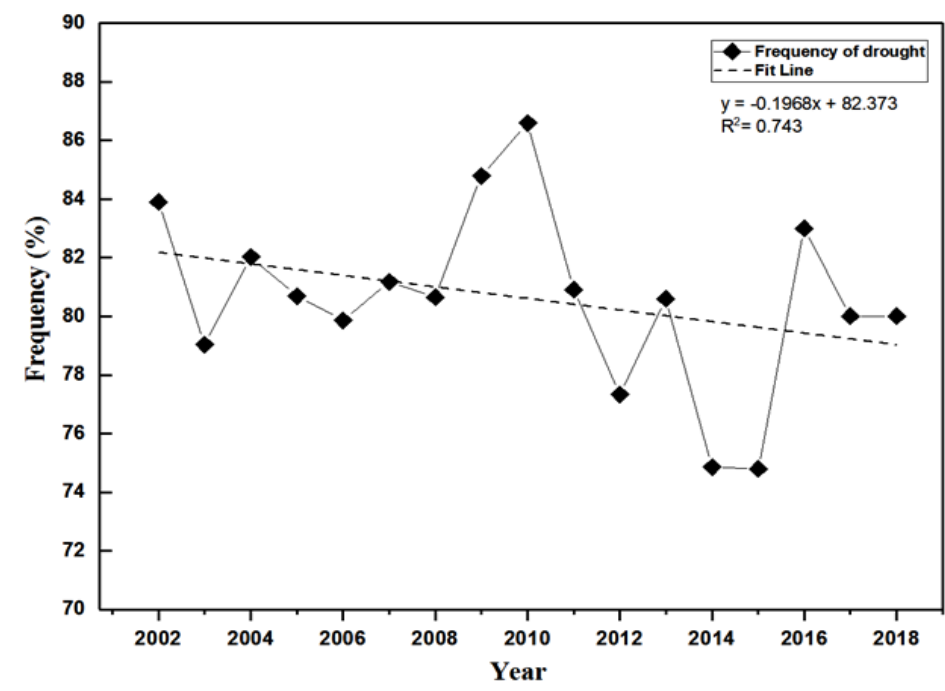

Figure 10. Frequency of drought occurrence trend in North and West Africa Between 2002 to 2018.

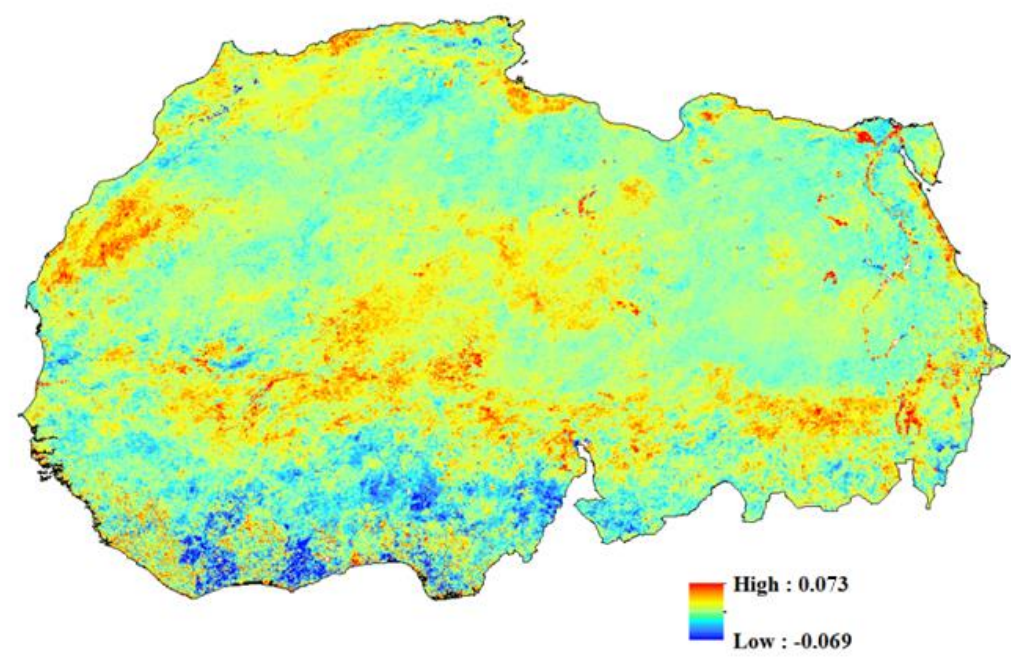

Figure 11. Distribution of the drought change trend in North and West Africa Between 2002 to 2018.

\subsection{Spatial correlation analysis}

The performance of the DSI and TVDI was analyzed by determining a seasonal spatial correlation analysis with NPA, TCI and NVSWI (Figure 12). All the study period was divided into four seasons: (1) autumn (SON), (2) winter (DJF), (3) spring (MAM) and (4) summer (JJA). The values of the correlation coefficient varied significantly between the four different growing seasons. The spatial correlation between DSI and NPA show negative values in the western region of Africa in Summer (JJA) and Autumn (SON). This explains that the DSI is not reliable to indicate a meteorological drought in this region. The spatial correlation between the two indexes DSI and NVSWI was significantly positive during spring (MAM), summer (JJA) and autumn (SON) seasons over North and West Africa and during the winter season (DJF) over West Africa. The spatial correlation between NDVI and NVSWI shows a positive correlation during winter (DJF), spring 
(MAM), summer (JJA) and autumn (SON) seasons. The association analysis between NVSWI and DSI and also between NVSWI and NDVI indexes revealed a significantly positive correlation values over the four seasons. This indicated an excellent sign of the drought monitoring, mainly for the vegetation in North and West Africa. While, the spatial correlation between TVDI and TCI shows a positive values during the winter (DJF) and autumn (SON) seasons in some parts of North Africa.

DJF
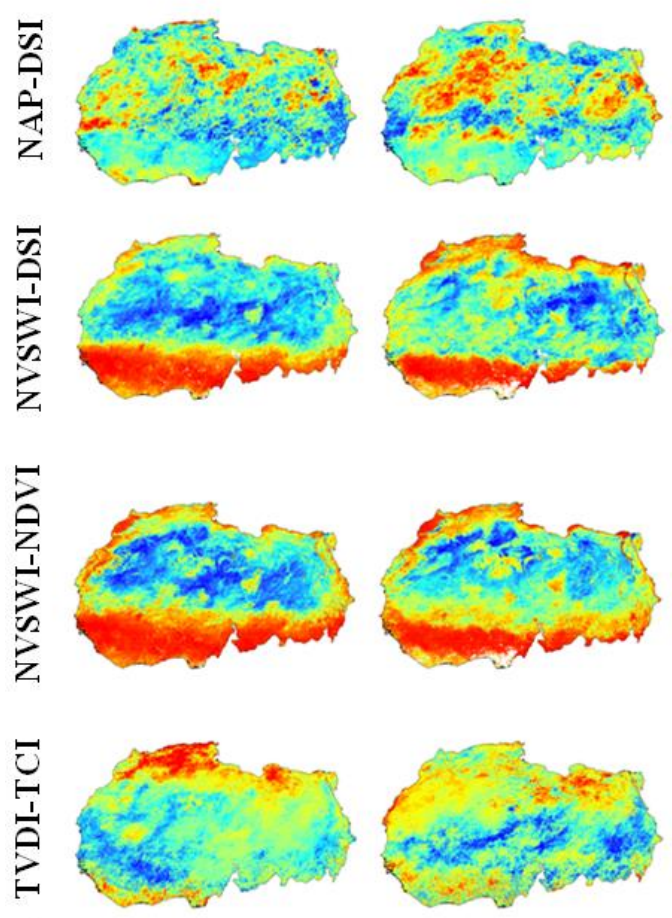

MAM
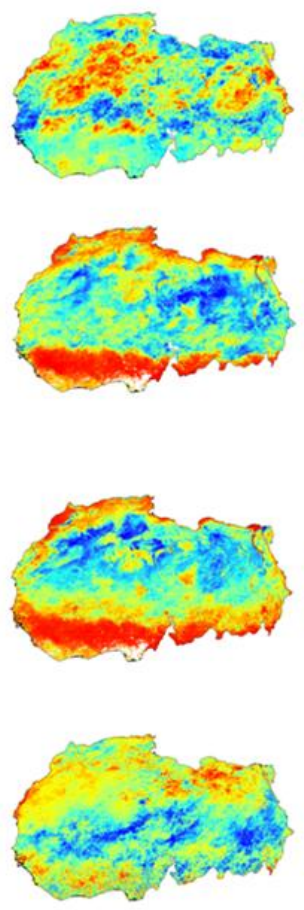

JJA
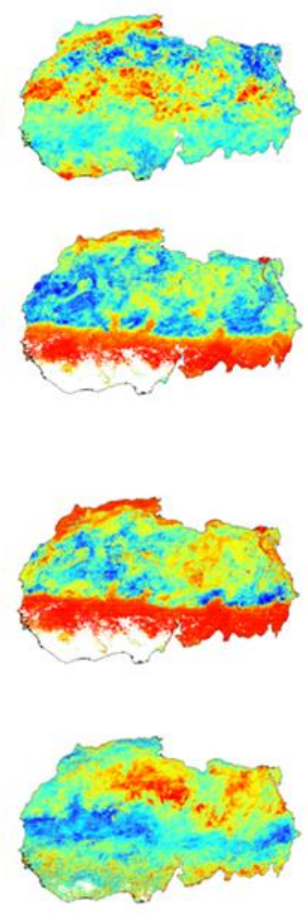

SON
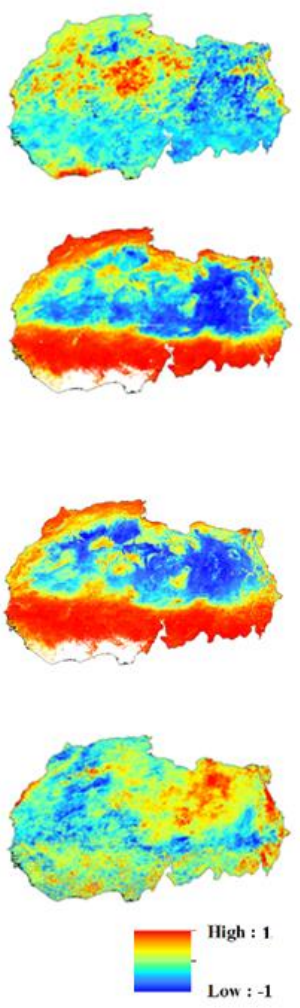

Figure 12. Spatial correlation coefficient values between seasonal A: (DJF) Dec-Feb, B: (MAM) MarMay, C: (JJA) Jun-Aug and D: (SON) Sep-Nov, DSI and NPA, DSI and NVWSI, NDVI and NVWSI, TVDI and TCI, over North and West Africa during (2002-2018).

The positive correlation at significant $\mathrm{OF}(\mathrm{P} \leq 0.05)$. The white patches on the map show unavailability of the data.

\section{Conclusion}

This study aimed to use remote sensing data and techniques along with TRMM data for consistent and reliable monitoring of drought in North and West Africa. Due to poor vegetation and dryness, the NDVI, TVDI, DSI and NVSWI drought indexes are more useful in describing the drought events in North and West Africa. To categorize drought-affected areas, the spatial maps of TRMM were used to confirm MODIS-derived TVDI, DSI, and NVSWI. For drought monitoring in North and West Africa, the NVSWI, DSI, TVDI, and NPA indexes were selected as a tool incorporated with MODIS-derived ET/PET and NDVI. The seasonal DSI, TVDI, NVSWI, NPA, TCI and NDVI values confirmed that North and West Africa suffered a severe drought in 2002, 2009, 2010 and 2016, The highest frequency of drought was observed in 2010 (86.59\%), the lowest frequency of drought was observed in 2014 (74.86\%) in our study area. On a seasonal basis, the correlation analyses were generated among DSI, NPA, NVSWI, NDVI, TVDI, and TCI. The significantly positive correlation values between the two indexes DSI and NVSWI was during MAM, JJA and SON seasons over North and West Africa and during DJF season over West Africa. The spatial correlation between NDVI and NVSWI shows a positive correlation during DJF, MAM, JJA and SON seasons. While, the positive correlation values between TVDI and TCI was during the 
winter (DJF) and autumn (SON) seasons in some parts of North Africa. This indicated that the NVSWI, NDVI and DSI present an excellent monitor of drought indexes during these seasons. In summer, it was reported that the drought was easier in the northern parts of Africa and in the Sahara than in the western region of Africa which shows a growing season of vegetation. The change trend of drought from 2002 to 2018 was also characterized. It is indicated that the change of drought trend was apparent among various parts of the regions, and overall the frequency of drought was reducing from 2002 to 2018. Since droughts are also influenced by numerous other climatic parameters, the interaction between drought and other climatic parameters should be investigated in our future research works.

Author Contributions: The manuscript was reviewed and approved for publication by all authors. JZ and MH conceived and designed the experiments. $\mathrm{MH}, \mathrm{QL}, \mathrm{SA}, \mathrm{WK}, \mathrm{SZ}$ and $\mathrm{YB}$ performed the experiments. $\mathrm{MH}$ and BE analyzed the data. $\mathrm{MH}$ wrote the paper. JZ, MH and $\mathrm{BE}$ reviewed and revised the paper. BE and JZ corrected the English language for the paper.

All authors have read and agreed to the published version of the manuscript.

Funding: This work was funded by the CAS Strategic Priority Research Program (No. XDA19030402) and the "Taishan Scholar" Project of Shandong Province and Key Basic Research Project of Shandong Natural Science Foundation of China (no. ZR2017ZB0422).

Acknowledgments: This work was funded by the CAS Strategic Priority Research Program (No. XDA19030402) and the "Taishan Scholar" Project of Shandong Province and Key Basic Research Project of Shandong Natural Science Foundation of China (no. ZR2017ZB0422).

Conflicts of Interest: The authors declare no conflict of interest.

\section{References}

1. Carrão H.; Naumann G.; Barbosa P. Mapping global patterns of drought risk: an empirical framework based on sub-national estimates of hazard, exposure and vulnerability. Glob Environ Chang 2016, 39, 108-124.

2. Mukherjee S.; Mishra A.; Trenberth K.E. Climate change and drought: a perspective on drought indices. Curr Clim Chang Rep 2018, 1-19.

3. Blauhut V.; Gudmundsson L.; Stahl K. Towards pan-European drought risk maps: quantifying the link between drought indices and reported drought impacts. Environ Res Lett 2015a, 10, 14008.

4. Stagge J.H.; Kohn I.; Tallaksen L.M.; Stahl K. Modeling drought impact occurrence based on meteorological drought indices in Europe. J Hydrol 2015, 530, 37-50.

5. Ahmadalipour A and Moradkhani H. Multi-dimensional assessment of drought vulnerability in Africa: 1960-2100. Sci Total Environ 2018a, 644, 520-535.

6. Kim J.; Waliser D.E.; Mattmann C.; Goodale C.E.; Hart A.F.; Zimdars P.A.; Crichton D.J.; Jones C.; Nikulin G.; Hewitson B. Evaluation of the CORDEX-Africa multi-RCM hindcast: systematic model errors. Clim Dyn 2014, 42, 1189-1202.

7. Vicente-Serrano S.M.; Begueria S.; Gimeno L.; Eklundh L.; Giuliani G.; Weston D.; El Kenawy A.; Lopez-Moreno J.I.; Nieto R.; Ayenew T. Challenges for drought mitigation in Africa: the potential use of geospatial data and drought information systems. Appl Geogr 2012, 34, 471-486.

8. Schilling J.; Freier K.P.; Hertig E.; Scheffran J. Climate change, vulnerability and adaptation in North Africa with focus on Morocco. Agric Ecosyst Environ 2012, 156, 12-26.

9. Nicholson S.E. A detailed look at the recent drought situation in the Greater Horn of Africa. J Arid Environ, 2014, 103, 71-79.

10. Nikiema P.M.; Sylla M.B.; Ogunjobi K.; Kebe I.; Gibba P.; Giorgi F. Multi-model CMIP5 and CORDEX simulations of historical summer temperature and precipitation variability over West Africa. Int $J$ Climatol, 2017, 37, 2438-2450.

11. Naumann G.; Barbosa P.; Garrote L.; Iglesias A.; Vogt J. Exploring drought vulnerability in Africa: an indicator based analysis to be used in early warning systems. Hydrol Earth Syst Sci, 2014a, 18, 15911604.

12. Naumann G.; Dutra E.; Barbosa P.; Pappenberger F.; Wetterhall F.; Vogt J.V. Comparison of drought indicators derived from multiple data sets over Africa. Hydrol Earth Syst Sci, 2014b, 18, 1625-1640. 
13. Lyon B. Seasonal drought in the Greater Horn of Africa and its recent increase during the March-May long rains. J Clim, 2014, 27, 7953-7975.

14. Godfray HCJ.; Beddington JR.; Crute I.R.; Haddad L.; Lawrence D.; Muir JF.; Pretty J.; Robinson S.; Thomas SM.; Toulmin C. Food security: the challenge of feeding billion people. Science, 2010, (80) 327, 812-818.

15. Khan ZR.; Midega CAO.; Pittchar JO.; Murage AW.; Birkett MA.; Bruce TJA.; Pickett JA. Achieving food security for one million sub-Saharan African poor through push-pull innovation by 2020. Philos Trans R Soc Lond Ser B Biol Sci, 2014, 369, 2012-284.

16. Rahimzadeh-Bajgiran P.; Berg A.A.; Champagne C.; Omasa K. Estimation of soil moisture using optical/thermal infrared remote sensing in the Canadian Prairies. ISPRS J Photogramm Remote Sens, 2013, 83, 94-103.

17. Muhammad A.H.; Fengmei Y.; Jiahua Z. Drought monitoring and performance evaluation of MODIS-based drought severity index (DSI) over Pakistan. Nat Hazards, 2016, 84:1349-1366.

18. Dianmin C.; Shuhe Z.; Cheng C.; Zheng D. Characterization of droughts during 2001-2014 based on remote sensing: A case study of Northeast China. Ecological Informatics, 2017, 39, 56-67.

19. Chen C.; Zhao S. Drought monitoring and analysis of Huanghuai Hai plain based on TRMM precipitation data. Remote Sens Land Res, 2016, 28 (1), 122-129.

20. Wan Z.; Wang P.; Li X. Using MODIS land surface temperature and normalized difference vegetation index products for monitoring drought in the southern Great Plains, USA. Int J Remote Sens, 2004, 25 $(1)$.

21. Tucker C.J.; Justice C.O.; Prince S.D. Monitoring the grasslands of the Sahel 1984-1985. Int J Remote Sens, 1986, 7 (11), 1571-1581.

22. Sandholt I.; Rasmussen K.; Andersen J. A simple interpretation of the surface temperature/vegetation index space for assessment of surface moisture status. Remote Sens Environ, 2002, 79 (2), 213-224.

23. Dhorde A.G.; Patel N.R. Spatio-temporal variation in terminal drought over western India using dryness index derived from long-term MODIS data. Ecological Informatics, 2016, 32, 28-38.

24. Carlson T.N.; Gillies R.R.; Perry E.M. A method to make use of thermal infrared temperature and NDVI measurements to infer surface soil water content and fractional vegetation cover. Remote Sens. Rev, 1994, 9 (1-2), 161-173.

25. Abbas S.; Nichol J.E.; Qamer F.M.; Xu J. Characterization of drought development through remote sensing: A case study in central Yunnan, China. Remote Sens, 2014, 6, 4998-5018.

26. Grant J.P.; Wigneron JP.; De Jeu R.A.M.; Lawrence H.; Mialon A.; Richaume P.; Kerr Y. Comparison of SMOS and AMSR-E vegetation optical depth to four MODIS based vegetation indices. Remote Sens Environ, 2016, 172, 87-100.

27. Mu Q.; Zhao M.; Kimball JS.; McDowell NG.; Running SW. A remotely sensed global terrestrial drought severity index. Bull Am Meteorol Soc, 2013, 94, 83-98.

28. Xu L.; Samanta A.; Costa MH.; Ganguly S.; Nemani RR.; Myneni RB. Widespread decline in greenness of Amazonian vegetation due to the 2010 drought. Geophys Res Lett, 2011, 38, L07402.

29. Jung M.; Reichstein M.; Ciais P.; Seneviratne SI.; Sheffield J.; Goulden ML.; Bonan G.; Cescatti A.; Chen J.; de Jeu R.; Dolman AJ.; Eugster W.; Gerten D.; Gianelle D.; Gobron N.; Heinke J.; Kimball J.; Law BE.; Montagnani L.; Mu Q.; Mueller B.; Oleson K.; Papale D.; Richardson AD.; Roupsard O.; Running S.; Tomelleri E.; Viovy N.; Weber U.; Williams C.; Wood E.; Zaehle S.; Zhang K. Recent decline in the global land evapotranspiration trend due to limited moisture supply. Nature, 2010, 467, 951-954.

30. Waha K.; Krummenauer L.; Adams S.; Aich V.; Baarsch F.; Coumou D.; Fader M.; Hoff H.; Jobbins G.; Marcus R. Climate change impacts in the Middle East and Northern Africa (MENA) region and their implications for vulnerable population groups. Reg Environ Chang, 2017, 17, 1623-1638.

31. Ahmadalipour A.; Moradkhani H. Escalating heat-stress mortality risk due to global warming in the Middle East and North Africa (MENA). Environ Int, 2018b, 117, 215-225.

32. Henchiri M.; Shahzad A.; Essifi B.; Kalisa W.; Zhang S.; Bai Y. Monitoring land cover change detection with NOAA-AVHRR and MODIS remotely sensed data in the North and West of Africa from 1982 to 2015. Envi Sci Pull Resea, 2019, DOI:10.1007/s11356-019-07216-1

33. Carlson T.N.; Perry E.M.; Schmugge T.J. Remote estimation of soil moisture availability and fractional vegetation cover for agricultural fields. Agric For Meteorol, 1990, 52, 45-69. 
34. Son N.T.; Chen C.F.; Chen C.R.; Chang L.Y.; Minh V.Q. Monitoring agricultural drought in the Lower Mekong Basin using MODIS NDVI and land surface temperature data. Int J Appl Earth Obs Geoinf, 2012, 18, 417-427.

35. Zhou L.; Tian Y.; Baidya Roy S.; Dai Y.; Chen H. Diurnal and seasonal variations of wind farm impacts on land surface temperature over western Texas. Clim Dyn, 2013, 41, 307-326.

36. Du L.; Tian Q.; Yu T.; Meng Q.; Jancso T.; Udvardy P.; Huang Y. A comprehensive drought monitoring method integrating MODIS and TRMM data. Int J Appl Earth Obs Geoinf, 2013, 23, 245-253.

37. Lambin E. F and Ehrlich D () The surface temperature-vegetation index space for land cover and land-cover change analysis. Int J Remote Sens, 1996, 17, 463-487.

38. Zhang SQ.; Qing QT.; Hou MT.; Feng JD. Remote sensing and impact estimation for Sichuan hot-drought based on temperature vegetation dryness index. Trans CSAE, 2007, (09):141-146-294.

39. Kogan FN. A typical pattern of vegetation conditions in southern Africa during El Nino years detected from AVHRR data using three channel numerical index. Int J Remote Sens, 1998, 19, 36883694.

40. Shao EY.; Bing-Fang W. Calculation of monthly precipitation anomaly percentage using web-serviced remote sensing data. Advanced computer control (ICACC), 2010 2nd international conference IEEE, 2010, 5, 621-625.

41. Jackson T.J.; Cosh M.H.; Bindlish R.; Starks P.J.; Bosch D.D.; Seyfried M.; Du J. Validation of advanced microwave scanning radiometer soil moisture products. IEEE Trans Geosci Remote Sens, 2010, 48 (12), 4256-4272.

42. Zhang J.; Mu Q.; Huang J. Assessing the remotely sensed Drought Severity Index for agricultural drought monitoring and impact analysis in North China. Ecol Indic, 2016, 63, 296-309.

43. Crow W.T.; Miralles D.G.; Cosh M.H. A quasi-global evaluation system for satellite based surface soil moisture retrievals. IEEE Trans Geosci Remote Sens, 2010, 48 (6), 2516-2527.

44. Song X.; Li L.; Fu G.; Li J.; Zhang A.; Liu W.; Zhang K. Spatial-temporal variations of spring drought based on spring-composite index values for the Songnen plain, Northeast China. Theor Appl Climatol, 2014, 116(3-4):371-384.

45. Jain S.K.; Keshri R.; Goswami A.; Sarkar A. Application of meteorological and vegetation indices for evaluation of drought impact: a case study for Rajasthan, India. Nat. Hazards, 2010, 54 (3), 643-656.

46. Wang J.; Price KP.; Rich PM. Spatial patterns of NDVI in response to precipitation and temperature in the central Great Plains. Int J Remote Sens, 2001, 22(18), 3827-3844. 